\title{
User-oriented elderly care: a validation study in two different settings using observational data
}

\author{
Ali Kazemi and Petri J. Kajonius
}

\author{
Ali Kazemi is Associate \\ Professor of Social Psychology \\ at the School of Health and \\ Education, University of \\ Skövde, Skövde, Sweden. \\ Petri J. Kajonius is Doctoral \\ Candidate at the Division of \\ Gerontology, Department of \\ Psychology, University of \\ Gothenburg, Gothenburg, \\ Sweden.
}

\begin{abstract}
Received 7 August 2014 Revised 5 January 2015 7 April 2015 Accepted 9 April 2015
\end{abstract}

(C) Ali Kazemi and Petri J. Kajonius. Published by Emerald Group Publishing Limited. This article is published under the Creative Commons Attribution (CC BY 3.0) licence. Anyone may reproduce, distribute, translate and create derivative works of this article (for both commercial \& noncommercial purposes), subject to full attribution to the original publication and authors. The full terms of this licence may be seen at http://creativecommons.org/ licences/by/3.0/legalcode.

This research was financially supported by grant 2012-1200 to Ali Kazemi from the Swedish Research Council for Health, Working Life and Welfare (FORTE, previously FAS). Acknowledgments and gratitude are also due to the motivated research assistants, Victoria Hörman and Martin Bäck, for their assistance in conducting the field-work.

\begin{abstract}
Purpose - User-oriented care, defined as individualized assisting behaviors, is the dominant approach within elderly care today. Yet, there is little known about its conceptual structure. This paper proposes that user-oriented care has a bi-partite structure which may be decomposed into the two dimensions of task and relation.

Design/methodology/approach - Care workers were "shadowed" (i.e. observed) at their work ( $n=391$ rated interactions). User-oriented care was assessed along ten process quality indicators targeting the acts of caregiving (i.e. task focus, relation focus, involvement, time-use, body language, autonomy, respect, warmth, encouragement, and information) in two elderly care settings, i.e. home care and nursing home. Observations added up to 45 hours.

Findings - Principal component analyses confirmed the proposed two-factor structure of user-oriented care. Specifically, the user-oriented care indicators loaded on two distinct factors, i.e. task and relation. The underlying structure of user-oriented care revealed to be invariant across the two settings. However, the results revealed interesting structural differences in terms of explained variance and the magnitude of factor loadings in the home care and nursing home settings. Differences also emerged specifically pertaining to the indicators of autonomy and time-use. These findings suggest that user-oriented behavior may to some extent denote different acts of caregiving and what may be called task- and relation-orientation may be loaded with different meanings in these two care settings.
\end{abstract}

Originality/value - This is the first study investigating user-oriented behavior in the context of elderly care using a quantitative observational approach. The authors propose that the observed differences between the two care settings are primarily not due to better elderly care work in home care, but due to some inherent differences between these two contexts of care (e.g. better health and living at home).

Keywords Elderly care, Home care, Nursing home, Individualized care, Person-centred care, Process quality, Relationship-centred care, User-orientation

Paper type Research paper

In 2013, 19.4 percent of Sweden's population was 65 or older indicating that Sweden proportionally has one of Europe's largest elderly populations. Sweden spends most in Europe on the elderly using home care and nursing home services (i.e. 2.5 percent of GNP) (European Commission, 2006) and is recognized for its generous state-run welfare system aiming at nationwide equality (Olsen, 2013; Theobald, 2003). Furthermore, Sweden has the highest proportion of older persons satisfied with their elderly care in Europe (National Board of Health and Welfare, 2012). In addition to the roles of technological and medical advances in recent years, another reason that is often expressed in the debate for high performance in Swedish elderly care - as shown in international as well as national comparisons over time - is the emergence and implementation of a user-oriented approach in contemporary elderly care 
(cf. National Board of Health and Welfare, 2008). Yet, there is little known about the conceptual components of user-oriented care. Therefore, the present study aims at examining the factorial/ conceptual structure of user-oriented care by observing and assessing care workers' behaviors in home care and nursing home settings. Previous research has revealed some noteworthy differences between these two settings (e.g. Kajonius and Kazemi, in press a, b). In addition to investigating the factorial structure of user-oriented care and its invariance across the care settings, mean scorings along a number of indicators targeting the acts of caregiving are compared between the two settings.

\section{Quality of care and user-orientation}

Quality of care is a constant subject of debate, yet there is no single agreed upon definition of quality of care or a universal recipe for achieving quality. One of the most well-known and well-cited conceptualizations of quality of care was offered by Donabedian (1988). According to Donabedian, quality of care is best described in terms of structure, process, and outcome (i.e. all the effects of care, such as health, knowledge, and satisfaction). Donabedian (1988) defines structure as the attributes of the context of care. In other words, structure refers to all factors affecting the conditions of caregiving, such as budget resources, staff training, and facilities. Process, on the other hand, implies all the acts of caregiving and indicates whether the right things were done in a correct way. Process quality has in previous research been operationalized in terms of interaction, communication, and decision-making occurring between the caregivers and the older persons (Fleishman, 1997; Forbes-Thompson and Gessert, 2005). Process variables are considered much more difficult to measure than structural variables (Closs and Tierney, 1993). The concept of user-oriented care, as introduced and assessed in the present study, can be subsumed under the umbrella term of care process quality.

User-orientation is usually associated with technical design and refers to the process in which the needs, wants, and limitations of end users of a product or a service are taken into account at different stages of the design process. In Sweden, this concept has also come to denote an emerging ideology in elderly care which bears close resemblance to what has previously in the literature been called individualized care or person-centered care (e.g. Kitwood, 1997; McCormack, 2004), but also to research on what has been called relationship-centered care (Nolan et al., 2004) and compassionate relationship-centered elderly care (Dewar and Nolan, 2013). The basic tenet of user-oriented care is also in line with what has recently been advanced and discussed as value-based health care (Porter, 2009). Since 2007, the National Board of Health and Welfare annually polls and reports on older persons' evaluations of elderly care on various quality indicators, and publishes the data in a report called Open Comparisons[1]. According to the National Board of Health and Welfare, user-orientation is a desirable approach in modern elderly care and stands for putting the older person and his/her needs at the center of the care personnel's attention, and that all due care is based on the older person's unique needs and preferences, not primarily on the care system's needs and preferences. User-orientation may be conceived of as a generic term aimed at encouraging user participation and the user being in control (Stewart, 2001). User-orientation denotes an active approach toward the elderly, an empowerment-oriented approach (e.g. Ghaye et al., 2000) characterized by a view that the elderly often are capable of taking active part in decision making and accomplishing everyday matters. By making the elderly an active part of the daily care services and give them "voice" (i.e. people feel fairly treated when they are granted an opportunity to voice their opinions, e.g. Lind et al., 1990), they experience personal worth and social status (cf. Lind and Tyler, 1988). Concepts of autonomy (e.g. Custer et al., 2012) and encouragement (Dewar and Nolan, 2013) are therefore central to the notion of user-oriented care.

Implementation of user-oriented care (stressing personal autonomy, dignity, respect, quality of life, etc.) is still an ongoing challenge for Swedish elderly care. For instance, Persson and Wästerfors (2009) showed that care staff in nursing homes neglected the residents' complaints and restricted older residents' autonomy to the extent that personal autonomy clashed with an efficient running of the nursing home. 


\section{The caring relationship}

The relationship between the older person (user/client) and the care assistant (care worker/staff) is an important foundation accounting for satisfaction with care among older persons (e.g. Senić and Marinković, 2012). Care assistants are nowadays expected to decode the needs of the older person and adapt their support thereafter. The fragile state of health that comes with increased age makes dependence on assistance inevitable. This relationship is further expected to be characterized by respect and integrity as well as continued autonomy for the older person (Murphy et al., 2007). However, this is something that staff in home care and nursing homes does not always reach up to, and major shortcomings are sometimes identified in users' participation and influence. These are often due to lack of time and staff, hurried and inflexible schedules, and care routines which make no room for discussions with the clients (cf. Persson and Wästerfors, 2009).

A characteristic of a functioning care relationship is the feeling of continued autonomy, for example, letting users decide mundane things like what clothes they will wear (Custers et al., 2011). Another key is the liberal sharing of information in the care relationships (Lothian and Philp, 2001), which, in turn, has been shown to lead to social well-being, enhanced self-image, and improved health and experience of care quality (Hellström and Sarvimäki, 2007). Inhibited information exchange is a hindrance to open and meaningful communication. In interacting with the elderly, not only verbal information is an issue, but also attitudes that are conveyed via body language. This engagement and commitment among assistance providers is considered to increase the quality of care (Tellis-Nayak, 2007). A negative attitude does not only lead to a worse perception of quality of care, but also that the user is deprived of their sense of dignity, autonomy, and even identity. Furthermore, physical contact in elderly care has been shown to have a positive impact on clients' well-being as well as their self-confidence and life satisfaction (Butts, 2001). Thus, forming sound and respectful interactions between older persons and caregivers, is pivotal for the future of elderly care quality (Lothian and Philp, 2001).

\section{The present study}

User-oriented care, defined as individualized assisting behaviors, is the dominant approach within elderly care today. Yet, previous research does not provide any guidance about its conceptual structure. Based on previous theorizing in the realm of social and industrial psychology (e.g. Bass and Stogdill, 1990; Fleishman, 1967; Furnham, 2003), and in contrast to lay conceptions equating user-orientation with relation-centered care, it is here proposed that user-oriented care has a bi-partite structure which may be decomposed into the two dimensions of task- and relation-orientation. The conceptual structure of user-oriented care was investigated by "shadowing" (i.e. observing) and assessing care workers' behaviors in 391 interactions along ten process quality indicators targeting the acts of caregiving in home care and nursing home settings. The factorial structure of user-oriented care and its invariance across the two settings of elderly care was examined using an exploratory approach. Mean scorings along the behavioral indicators were also compared between home care and nursing home observations.

\section{Methods}

Behavioral research studies are often conducted using self-assessing surveys based on convenience sampling. Observation of actual behaviors (in natural settings) is often lacking in the social sciences (Baumeister et al., 2007). A plethora of observational approaches have been discussed in the methods literature. There are observational approaches aiming at promoting researcher-participant co-construction of what is observed and how these are interpreted such as visual ethnography (e.g. Pink, 2007), and there are less interactional observational approaches such as the third-party observer approach. The latter approach was used in the present study as the primary aim was to collect data on how care workers were perceived, and employing a more interactional observation approach in which the care workers were made more active in the research process would have been less relevant to the present research's primary aim. Being present but not actively involved as an observer provided the basis for making thorough ratings on ten indicators of user-oriented care. 
Care workers were followed or "shadowed" in their daily activities and interactions with the older persons and the observers rated the care workers' behaviors along various aspects of care. There has been a recent interest for using shadowing in research (see McDonald and Simpson, 2014). Usually, having an observing third-party present (i.e. a potential source of interference to daily routines) may interfere with the situation at hand and thus pose a threat to valid conclusions. However, this was not the case as the care workers and the older persons were used to regularly have trainees following their daily schedules (routines and activities).

\section{Observing procedure}

A medium-sized municipality (50,000 inhabitants, being among the 50 largest cities in Sweden) was selected; ranked as an average municipality for two consecutive years in terms of user-oriented care in both home care and nursing homes (National Board of Health and Welfare, 2012). The municipality was considered being nationally representative in terms of its size. Elderly care in this municipality was divided into six home care units and seven nursing home units, each unit with its own management. One representative unit of each care setting was chosen in collaboration with the head of the care department at the municipal level, after having informed the managers about the upcoming research project and asking for permission for two research assistants following care workers in their daily schedules. The managers obtained verbal consent for the observations from the care workers and the care workers obtained verbal consent from the older persons. For instance, before entering an older person's home in home care, the care workers asked the older person whether they approved them bringing an observing assistant into their home. All care workers and older persons agreed to the observations.

Four days of observation were scheduled - two days at a home care unit, and two days at a nursing home, the latter also containing older persons suffering from dementia. The vast majority of the older persons were above 80 years old. The expected duration of stay before death at the nursing home was approximately two years. The care workers were mostly women (> 90 percent), and the range of experience was anywhere from having recently started to over 30 years of work experience within the municipality. The research assistants were free to choose any shift (i.e. morning, day, evening, weekend). At the start of each day, the research assistants were paired with a nursing assistant/care worker who was on duty that particular day during the morning. After the break and lunch, the research assistants were free to choose to follow another care worker. A convenience sampling strategy with the aim of following and observing as many different care workers as possible was employed.

Two research assistants, a male and a female, 24 and 30 years of age, respectively, who had not been involved in the design of the study, were chosen and trained for conducting the observations. Their instructions were simply to "shadow" the care workers and to rate their behaviors along ten aspects of care. Ensuring the richness of data, the two research assistants conducted their observations individually. However, before starting the study, the two research assistants conducted a number of pilot observations, and in collaboration with the researchers the observation instrument was calibrated and inter-rater consistency was checked. No significant differences in their ratings were detected. After each observation session they further discussed their observations to ensure they were rating the same behavioral cues. A dozen different care workers were observed in interaction with the older persons during four days and a total of 391 interactions were recorded (175 in home care and 216 in the nursing home setting). Wake-up time, assisting with hygiene, conversations at the dinner-table, and going for a walk were some examples of the observed interactions. No interaction occurred between care workers and observers during these recordings. Field notes were taken during the observation sessions. Care worker behaviors were furthermore rated along ten process quality indicators which will be described in the following section. Observations added up to 45 hours.

\section{Observation instrument}

The observation instrument included ten process quality indicators tapping user-oriented care among home care and nursing home staff. These were based on items from previous national surveys on elderly care (National Board of Health and Welfare, 2012), and characteristics of 
caring relationships discussed in the literature (e.g. Caris-Verhallen et al., 1999; Custers et al., 2011; Dewar and Nolan, 2013; Lothian and Philp, 2001; Nolan et al., 2004). All process quality indicators were rated on a scale of $1-5(1=$ not at all and $5=$ to a large extent). The process indicators were: task focus (assisting behaviors necessary to perform the expected work in a particular situation); relation focus (voluntary acts of care considered as not necessary for performing the work falling outside the scope of the caregivers' formal responsibilities. These services are provided as they contribute to the overall comfort of the older person, to do "that little bit extra"); involvement (commitment and engagement shown in the interactions with the user); time-use (allocation of time and perceived efficiency in the interaction with the user); body language (posture, facial expressions, and movements in the interactions); autonomy (the act of taking into account users' opinions and preferences and personalizing the care thereafter); respect (an approach characterized by maintaining the integrity and privacy of the user and their situation); warmth (kindness and informality in the interactions with the user); encouragement (an approach characterized by a positive attitude toward the user and his/her competence and efforts to empower and enable the user); and information (the amount and quality of the information communicated by the care worker to the user). The research assistants rated the extent to which a specific behavior was shown by the care worker in a particular interaction with the older person the way they perceived it in their capacities as impartial non-participatory observers.

\section{Statistical approach}

In addition to using correlational analyses (Pearson's $r$ ) and independent samples $t$-tests for comparing differences, principal component analysis (PCA) with oblique rotation (direct oblimin) was used to analyze the underlying structure of the user-oriented care indicators outlined above in two different elderly care settings using observational data of care workers' behaviors toward the older persons. Oblique rotation for extraction of components, in contrast to orthogonal, does not impose the arbitrary restriction that factors do not correlate. A two-factor solution inspired by a long-lasting line of research within the fields of social and industrial psychology distinguishing between two major orientations toward task-related and relational or socio-emotional aspects of work (e.g. Bass and Stogdill, 1990; Fleishman, 1967; Furnham, 2003) was specified.

The factor loadings should be interpreted as the regression coefficients for each variable on each factor (as reported data are based factor loadings in a pattern matrix) and measures the strength of the relationship between the variables and the latent factors (i.e. extracted components) or the relative contribution that a variable makes to a factor (Field, 2013).

Kaiser-Meyer-Olkin (KMO) measure of sampling adequacy was checked prior to the PCA. KMO is the ratio of the squared correlation between variables to the squared partial correlation between variables, and varies between 0 and 1. Thus, the larger the sum of partial correlations is relative to the sum of squared correlations, the closer to 1 the $\mathrm{KMO}$ statistic will be, indicating that factor analysis or PCA should yield distinct and reliable factors. $\mathrm{KMO}$ values of 0.77 and 0.65 were obtained for nursing home and home care data, respectively, which exceeded the cut-off point of 0.5 , indicating the adequacy of performing a PCA on the data in both samples. Furthermore, item selection was guided by positive factor loadings $\geqslant 0.30$ criterion.

\section{Results}

Table I shows the correlations between the indicators of user-oriented care in the nursing home sample, and Table II shows the correlations in the home care sample.

In general, stronger associations between the variables were observed in the nursing home setting than in the home care setting. Another interesting observation was the negative correlation between task and relation foci, that is, the more the care worker adopted a task focus, the less was the relation focus. This correlation was consistent across the two settings. There were some other noteworthy observations concerning the patterns of association between the task focus and the other variables, and between the relation focus and the other variables in the observing scheme. In both care settings, information was positively related to task focus. Moreover, autonomy was positively associated with task focus in the nursing home sample but not in home care. In contrast, there were no significant associations between relation focus on the 
Table I Bivariate correlations between user-oriented care indicators in nursing home

\begin{tabular}{|c|c|c|c|c|c|c|c|c|c|c|}
\hline \multicolumn{11}{|c|}{ Correlations } \\
\hline Variable & 1 & 2 & 3 & 4 & 5 & 6 & 7 & 8 & 9 & 10 \\
\hline 1. Task focus & 1 & & & & & & & & & \\
\hline 2. Relation focus & $-0.49^{\star \star}$ & 1 & & & & & & & & \\
\hline 3. Involvement & $-0.19^{\star \star}$ & $0.66^{\star \star}$ & 0.1 & & & & & & & \\
\hline 4. Time-use & $0.17^{\star}$ & $0.19^{\star \star}$ & $0.31^{\star \star}$ & 1 & & & & & & \\
\hline 5. Body language & 0.08 & $0.39^{\star \star}$ & $0.57^{\star \star}$ & $0.44^{\star \star}$ & 1 & & & & & \\
\hline 6. Autonomy & $0.25^{\star \star}$ & 0.02 & $0.16^{\star}$ & -0.05 & $0.18^{\star \star}$ & 1 & & & & \\
\hline 7. Respect & -0.05 & $0.43^{\star \star}$ & $0.48^{\star \star}$ & $0.26^{\star \star}$ & $0.48^{\star *}$ & $0.36^{\star \star}$ & 1 & & & \\
\hline 8. Warmth & $-0.21^{\star \star}$ & $0.65^{\star \star}$ & $0.71^{\star \star}$ & $0.18^{\star \star}$ & $0.56^{\star \star}$ & $0.29^{\star \star}$ & $0.67^{\star \star}$ & 1 & & \\
\hline 9. Encouragement & $0.25^{\star \star}$ & 0.01 & $0.14^{\star}$ & 0.04 & $0.20^{\star \star}$ & $0.61^{\star *}$ & $0.27^{\star \star}$ & $0.23^{\star \star}$ & 1 & \\
\hline 10. Information & $0.33^{\star \star}$ & 0.04 & 0.12 & $0.20^{\star \star}$ & $0.24^{\star \star}$ & $0.14^{\star}$ & 0.10 & 0.10 & $0.22^{\star \star}$ & 1 \\
\hline
\end{tabular}

Table II Bivariate correlations between user-oriented care indicators in home care

\begin{tabular}{|c|c|c|c|c|c|c|c|c|c|c|}
\hline \multicolumn{11}{|c|}{ Correlations } \\
\hline Variable & 1 & 2 & 3 & 4 & 5 & 6 & 7 & 8 & 9 & 10 \\
\hline 1. Task focus & 1 & & & & & & & & & \\
\hline 2. Relation focus & $-0.47^{\star \star}$ & 1 & & & & & & & & \\
\hline 3. Involvement & $-0.26^{\star \star}$ & $0.49^{\star \star}$ & 0.1 & & & & & & & \\
\hline 4. Time-use & $0.26^{\star}$ & $0.15^{\star}$ & $0.23^{\star *}$ & 1 & & & & & & \\
\hline 5. Body language & -0.13 & $0.29^{\star *}$ & $0.39^{* \star}$ & $0.28^{\star \star}$ & 1 & & & & & \\
\hline 6. Autonomy & -0.02 & 0.09 & 0.11 & -0.01 & $0.16^{\star}$ & 1 & & & & \\
\hline 7. Respect & -0.02 & $0.30^{\star *}$ & $0.26^{\star \star}$ & 0.12 & 0.14 & $0.21^{\star \star}$ & 1 & & & \\
\hline 8. Warmth & $-0.23^{\star \star}$ & $0.48^{\star *}$ & $0.61^{* \star}$ & 0.11 & $0.25^{\star \star}$ & 0.15 & $0.36^{\star \star}$ & 1 & & \\
\hline 9. Encouragement & 0.05 & -0.02 & 0.05 & $0.16^{\star}$ & 0.06 & $0.44^{\star \star}$ & 0.12 & 0.12 & 1 & \\
\hline 10. Information & $0.33^{\star \star}$ & -0.06 & 0.06 & $0.19^{*}$ & 0.10 & -0.06 & 0.02 & 0.04 & 0.03 & 1 \\
\hline
\end{tabular}

one hand, information and autonomy on the other. Variables most strongly associated with relation focus were involvement, warmth, and respect in both settings. Whereas all these associations were positive, involvement, and warmth were negatively associated with task focus. Respect was not significantly associated with task focus. The same held for body language, that is, whereas body language was positively associated with relation focus in both care settings, no statistically significant relationship was found between body language and task focus.

\section{PCA}

To gain a deeper understanding of the correlations between the study variables and the observed differences across the two elderly care settings outlined above, two PCA, one in each sample, were conducted to explore the factorial, underlying, structure of collected data. The results from these two analyses are presented in Tables III and IV for nursing home and home care observations, respectively.

In the nursing home sample, the first component (relation) accounted for 36.4 percent, and the second (task) for 20 percent of the variance (i.e. total variance explained was 56.4 percent). Correspondingly, in the home care sample, relation accounted for 27.7 percent, and task for 16.6 percent of the variance (i.e. total variance explained was 44.3 percent). Given the larger amount of variance accounted for in the nursing home sample, these results may indicate that user-oriented care was better represented and its content more satisfactorily captured by the indicators. In sum, the proposed two-factor structure of user-orientation was partially supported. 
Table III Summary of principal component analysis of user-oriented care indicators in nursing home

Item

Relation

Task

Task focus

$-0.37$

0.78

Relation focus

0.84

$-0.38$

Involvement

0.86

$-0.08$

Time-use

0.38

0.16

Body language

0.69

0.22

Autonomy

0.18

0.67

Respect

0.72

0.19

Warmth

0.89

$-0.00$

Encouragement

0.14

0.71

Information

0.09

Eigenvalue

3.64

2.00

$\%$ of variance explained

36.39

20.03

Cumulative $\%$ of variance explained

36.39

Notes: $n=216$. Inter-factor correlation was 0.15 (i.e. a weak correlation)

\section{Table IV Summary of principal component analysis of user-oriented care indicators} in home care

\begin{tabular}{lrr} 
Item & Relation & Task \\
\hline Task focus & -0.50 & 0.75 \\
Relation focus & 0.79 & -0.30 \\
Involvement & 0.80 & -0.02 \\
Time-use & 0.22 & 0.60 \\
Body language & 0.53 & 0.19 \\
Autonomy & 0.29 & 0.26 \\
Respect & 0.50 & 0.16 \\
Warmth & 0.78 & -0.04 \\
Encouragement & 0.16 & 0.45 \\
Information & -0.07 & 0.59 \\
Eigenvalue & 2.77 & 1.66 \\
\% of variance explained & 27.73 & 16.61 \\
Cumulative \% of variance explained & 27.73 & 44.34 \\
Notes: $n=175$. Inter-factor correlation was 0.14 (i.e. a weak correlation) &
\end{tabular}

The inter-factor correlations were 0.15 (for nursing home observations) and 0.14 (for home care observations), indicating the distinct and independent nature of the extracted components.

Factor loadings indicate the relative contribution of each item to the extracted factors. In other words, the magnitude of factor loadings reveals that some items are more important than others and are therefore more representative for their underlying factor. Warmth, involvement, relation focus, respect, and body language loaded positively and highly on the extracted relation-orientation component, whereas task focus, information, and encouragement loaded on the extracted task-orientation component. These patterns of loadings were consistent across the two care settings. Warmth and involvement were the two indicators with the highest factor loadings on the relation-orientation component in the nursing home and home care samples, respectively. Task focus loaded highest on the task-orientation component in both samples.

There were, however, some setting-specific patterns indicating differences between nursing home and home care. Specifically, autonomy loaded on the task component in the nursing home sample, but not in the home care sample. Moreover, time-use loaded - somewhat unexpectedly - differentially in the two samples. In the nursing home sample, time-use loaded on the relation-orientation component, whereas in the home care sample it loaded on the 
task-orientation component. In further explorations of differences between the two care settings, there were two other noteworthy findings. First, respect showed to be a much stronger indicator of relation-orientation in the nursing home setting (0.72) than in the home care setting (0.50). Second, encouragement revealed to be a much stronger indicator of task-orientation in the nursing home setting $(0.71)$ than in the home care setting $(0.45)$. There were other differences but the absolute sizes of these were not as large as for the respect and encouragement indicators.

\section{Independent samples t-tests}

Table $V$ depicts descriptive differences for the variables in the observing scheme between the nursing home and home care samples. Care workers were overall perceived to show very high levels (i.e. above 4.5 on the five-point rating scale) of respect, warmth, and involvement. Respect was rated as the most frequently (means $=4.82$ and 4.94) and encouragement as the least frequently (means $=3.54$ and 3.51) observed behaviors in both care settings. Interestingly, relation focus was overall rated as being more prevalent (means $=4.18$ and 4.22 ) than task focus (means $=3.60$ and 3.87). However, the standard deviations for task focus were consistently higher, indicating larger variations in task focus $(\mathrm{SDs}=1.69$ and 1.52) than in relation focus ( $\mathrm{SDs}=1.09$ and 1.05) among the care workers in both care settings.

Using independent samples $t$-tests, statistically significant differences emerged in ratings of five items between the two care settings. Home care staff were scored higher on time-use, information, warmth, and respect than the nursing home staff. Body language was the only variable on which the nursing home staff was scored higher by the observers than the home care staff. All these differences were statistically significant but small in absolute size, in that the mean differences ranged from 0.12 to 0.35 .

\section{Discussion}

To our knowledge, this is the first study which has used a non-participatory observation approach to assess behavioral indicators of user-orientation in the context of elderly care. Moreover, data were analyzed for differences and similarities in the underlying structure of the construct of userorientation but also differences in care workers' behaviors in the nursing home and home care settings. In a way, the third-party (external observer) perspective on care workers' user-oriented behaviors confirms the validity of previous findings concerning older persons' impressions of the quality of elderly care (Kajonius and Kazemi, in press a). That is, that older persons in home care are more satisfied with care than older residents in nursing homes (Kajonius and Kazemi, in press b; see also Berglund, 2007). In a similar vein but using another methodological approach (i.e. the observations of uninformed research assistants using a double-blind design, that is, neither party knew what patterns of ratings were expected), the present study found that on some

\begin{tabular}{|c|c|c|c|c|c|c|}
\hline Variable & $\begin{array}{c}\text { Nursing home } \\
M\end{array}$ & $S D$ & $\begin{array}{c}\text { Home care } \\
M\end{array}$ & $S D$ & $t$ & $p$ \\
\hline Task focus & 3.60 & 1.69 & 3.87 & 1.52 & -1.6 & 0.11 \\
\hline Relation focus & 4.18 & 1.09 & 4.22 & 1.05 & -0.3 & 0.73 \\
\hline Involvement & 4.59 & 0.68 & 4.63 & 0.67 & -0.4 & 0.73 \\
\hline Time-use ${ }^{\star \star}$ & 3.85 & 0.96 & 4.20 & 1.03 & -3.5 & 0.00 \\
\hline Body language* & 4.15 & 0.85 & 3.95 & 0.97 & 2.2 & 0.03 \\
\hline Autonomy & 4.00 & 1.05 & 3.97 & 1.16 & 0.6 & 0.26 \\
\hline Respect $^{*}$ & 4.82 & 0.58 & 4.94 & 0.28 & -2.7 & 0.01 \\
\hline Warmth ${ }^{\star \star}$ & 4.63 & 0.72 & 4.82 & 0.47 & -3.1 & 0.00 \\
\hline Encouragement & 3.54 & 0.84 & 3.51 & 0.86 & 0.9 & 0.42 \\
\hline Information* & 3.74 & 0.87 & 4.00 & 1.12 & -2.5 & 0.01 \\
\hline
\end{tabular}


user-oriented indicators the home care staff scored higher than the nursing home staff, although these differences in absolute size were small. This validation of previously reported findings in the literature may to some extent overshadow one possible limitation of the present study, and that is, the observations were conducted at only two units in one municipality. The novelty and the strength of the present study lies to some extent in its using naturalistic actual behavior observations by external observers (often lacking in the social sciences as noted by Baumeister et al., 2007) and confirming previous results obtained from self-reported surveys responded to by older persons, which should besides its contribution to research also be of interest to policy makers.

Why do these differences exist between home care and nursing homes? Previous research shows that evaluation of care is directly affected by the personal conditions of the older person in terms of health and anxiety (see Kajonius and Kazemi, in press a; Otani et al., 2012). Older persons living at home are typically healthier, independent, and expect to be treated like other citizens. When admitted into a nursing home, older persons usually suffer from physical ailments and heightened anxiety which tend to lower evaluations of the caring relationship (e.g. Fleishman, 1997). Furthermore, the elderly's expectations might be high when moving into sheltered housing and to the extent that these positively high expectations are not met, the evaluations of quality of care are even more adversely affected (cf. Szymanski and Henard, 2001). Another tenable account of these differences, although not empirically addressed to our knowledge in previous research, is the prolonged contact inherent in nursing home work might adversely affect how older persons are treated, as compared to the briefer meetings in home care.

\section{Factorial validity of user-orientation in the context of elderly care}

Besides the aim of comparing how care workers in home care and nursing home settings behaved toward the older person in different types of situations occurring during the time care was provided, another important purpose of the present study was to investigate the factorial validity of user-oriented care using an exploratory approach (see Fabrigar et al., 1999) in the two care settings. This latter aim is more fundamental as mean differences in assessed indicators between settings cannot be interpreted meaningfully unless the underlying structure of this construct reveals to be invariant across the two settings. The proposed two-factor structure (e.g. Furnham, 2003) was corroborated, and the pattern of item loadings on the extracted factors of task- and relation-orientation showed to be similar except for the two items of autonomy and time-use. Autonomy single-loaded on the task-orientation component only in the nursing home sample and time-use loaded on the relation-orientation component for nursing home observations, and on the task-orientation component for the home care observations. In sum, the measurement invariance (i.e. consistent pattern of factor loadings across settings) rendered validity and meaningful interpretations to the statistically significant mean differences for the indicators across the two settings, except for the variable of time-use. Moreover, the relationorientation component was shown to be a much more salient and important dimension of user-oriented elderly care than the task-orientation component, as indicated by the eigenvalues and the amounts of variance that the relation- and task-orientation components, respectively, explained in both elderly care settings.

Although the two-factor solution provided the most parsimonious and theoretically meaningful modeling of the data, the amounts of explained variance were in both samples below what was initially expected. However, this finding is indicative of the multi-faceted nature of the user-orientation construct as more than half of the total variance remained unexplained in the home care sample - a finding that may suggest that there is more to user-orientation than what was covered by the ten behavioral indicators used in the present study. Thus, it is suggested that future research attempts at developing a more comprehensive measure of user-orientation and validate its conceptual structure using confirmatory factor analysis (CFA). The main differences between the exploratory and the confirmatory approaches are that in the latter approach each and every item is set to load on a predefined factor only (i.e. no simultaneous loadings on several factors are allowed) and the calculation of model fit indices, that is, the discrepancy in covariance structures of observed data and the defined model (Barrett, 2007; Hu and Bentler, 1999). It should, however, be noted that using CFA requires a good theory and should if possible be 
applied to established scales. Data fishing (also referred to as equation fitting) using CFA aiming at seeking any associations between data, maximizing explained variance and/or estimating models which provide excellent model fit is not a good research practice, as peculiarities of a certain data set may uncover relationships between sets of variables which may be difficult, if not impossible, to replicate and generalize to other settings. Utilizing theory and theoretical arguments prevents us from drawing premature and misleading conclusions and help us in generating and meaningfully interpreting reliable findings to inform practice and policy making.

It is further suggested that the notion of user-oriented elderly care is expanded in future investigations to encompass (and to a larger extent highlight) the impact of the staff-user interaction in producing various outcomes such as satisfaction, anxiety, and so forth instead of only targeting the care workers' patterns of behavior toward the elderly. Conceived in this way, care is formed and re-formed constantly in the interaction, and cannot be conceived as a one-way road.

Another suggestion for future research is to further investigate the setting- and context-specific (organizational) contingencies of home care and nursing homes for producing and successfully implementing user-oriented care.

\section{Successful user-oriented care: treating the elderly the way they like and want to be treated}

All the ten process quality indicators assessed in the present study could be conceived as different elements, which, to varying degrees, contribute to the perception of user-oriented care from the points of view of external observers (e.g. close relatives) but also those of the older persons. The relatively high ratings of process quality indicators by the observers can be conceived as validations of a successfully implemented user-oriented elderly care. Specifically, very high levels of respect, warmth, and involvement were observed among the care workers in both home care and nursing home.

Furthermore, the relation-orientation factor accounted for a larger amount of variance in the data and was thus more focal for user-oriented care in both settings. This suggested that in addressing the needs of the elderly and performing individualized assisting behaviors, relationship comes first and task comes second. Interestingly, information provision was shown to be an indicator of task-orientation. This may indicate that communicating with the elderly about care planning has come to be incorporated in what care workers define as their work tasks, that is, providing information in different ways (e.g. feedback, feed-forward) is an integral part of the work which in turn should be seen as a good sign because informing about the process, routines, and activities of care are almost as important as performing the care itself. Moreover, care workers may not always consider "relation" aspects of care as part of their job. For instance, care workers may not perform relationship-oriented behaviors like sitting next to the older person because they do not define these acts of caring as "real work." That is, if the time allows they will use the time to perform more tangible acts of care like cooking, cleaning, or doing the laundry. In this way, the care workers can feel satisfied with having done their job conscientiously. It was noteworthy, that encouragement loaded somewhat unexpectedly on the task-orientation factor, suggesting that care workers seemed to define a positive attitude toward the user and making efforts to empower and enable the older person as an integral part of their work tasks and thus invest time in it; something which could be interpreted as a sign of quality improvement in a sector traditionally characterized by viewing older persons as passive and generally incapable.

We will now briefly comment on the observed findings on time-use in home care and body language in nursing home. Current results seem to suggest that time-use was a much stronger indicator of task-orientation in the home care than as an indicator of relation-orientation in the nursing home observations (see factor loadings in Tables IV and V). The stronger impact of time-use as a task indicator (i.e. allocation of time and perceived efficiency in the interaction with the older person) in home care could mean that home care staff only has a minimum amount of time as compared to nursing home staff to manage the older person's daily schedule. However, it should be noted that limited time in itself could be a potential barrier to adopting a user-oriented care approach in home care at the same time that one of the essentials of the user-oriented care approach (i.e. "knowing the person") is more easily realized, something which could be facilitated 
in home care as long as staff turnover is low. Furthermore, body language was more pronounced in the nursing home setting, perhaps due to the care atmosphere and the nature of the clientele (e.g. slower pace, relaxed atmosphere, and elderly suffering from dementia). It is therefore advised that nursing home staffs are offered opportunities to acquire deeper knowledge about how to use their body and its language more consciously and purposefully. Given these and other previously described differences between the home care and nursing home samples reported herein, it is suggested that these two types of elderly care are separated when researchers and policy makers analyze outcomes of various quality measures taken, plan for future elderly care and interpret the results of polls on user-oriented care, such as the annual poll of the National Board of Health and Welfare.

\section{Coda}

In conclusion, the old adage of "Do unto others as you would have them do unto you" which has gained credit through long use, may have to be revised and reformulated as "Treat others (read elderly) as they like to be treated and not as you want to be treated." Besides not using one's own preferences as a point of anchor for providing care, policy makers, and elderly care practitioners should be reminded that regulations and regulatory documents should never be used as an excuse for being unresponsive to personal needs of the elderly nor to build a barrier to implementing user-oriented care (cf. Hunter, 2004). This could have parallels in the midwifery literature, where user-oriented care is discussed in terms of the "with woman" care ideology in contrast to "with institution" care ideology). We here argue for care which is more clearly "with the person with dementia."

\section{Note}

1. In the poll from 2012, a questionnaire was sent out to 95,000 individuals using elderly care services. The response rates were 70 and 54 percent in home care and nursing homes, respectively.

\section{References}

Barrett, P. (2007), "Structural equation modelling: adjudging model fit", Personality and Individual Differences, Vol. 42 No. 5, pp. 815-24.

Bass, B.M. and Stogdill, R.M. (1990), Handbook of Leadership: Theory, Research, and Managerial Applications, 3rd ed., Free Press, New York, NY.

Baumeister, R.F., Vohs, K.D. and Funder, D.C. (2007), "Psychology as the science of self-reports and finger movements: whatever happened to actual behavior?”, Perspectives on Psychological Science, Vol. 2 No. 4, pp. 396-403.

Berglund, A.L. (2007), "Satisfaction with caring and living conditions in nursing homes: views of elderly persons, next of kin and staff members", International Journal of Nursing Practice, Vol. 13 No. 1, pp. 46-51.

Butts, J.B. (2001), "Outcomes of comfort touch in institutionalized elderly female residents", Geriatric Nursing, Vol. 22 No. 4, pp. 180-4.

Caris-Verhallen, W.M., Kerkstra, A. and Bensing, J.M. (1999), "Non-verbal behaviour in nurse-elderly patient communication", Journal of Advanced Nursing, Vol. 29 No. 4, pp. 808-18.

Closs, S.J. and Tierney, A.J. (1993), "The complexities of using a structure, process and outcome framework: the case of an evaluation of discharge planning for elderly patients", Journal of Advanced Nursing, Vol. 18 No. 8, pp. 1279-87.

Custers, A.F., Kuin, Y., Riksen-Walraven, M. and Westerhof, G.J. (2011), "Need support and wellbeing during morning care activities: an observational study on resident-staff interaction in nursing homes", Ageing and Society, Vol. 31 No. 8, pp. 1425-42.

Custers, A.F.J., Westerhof, G.J., Kuin, Y., Gerritsen, D.L. and Riksen-Walraven, M. (2012), "Relatedness, autonomy and competence in the caring relationship: the perspective of nursing home residents", Journal of Aging Studies, Vol. 26 No. 3, pp. 319-26. 
Dewar, B. and Nolan, M. (2013), "Caring about caring: developing a model to implement compassionate relationship centred care in an older people care setting", International Journal of Nursing Studies, Vol. 50 No. 9, pp. 1247-58.

Donabedian, A. (1988), "The quality of care: how can it be assessed?", Jama, Vol. 260 No. 12, pp. 1743-8.

European Commission (2006), "Directorate-general for economic, \& economic policy committee of the european communities", The Impact of Ageing on Public Expenditure: Projections for the EU-25 Member States on Pensions, Healthcare, Long-Term Care, Education and Unemployment Transfers (2004-50), Office for Official Publications of the European Communities, Brussels.

Fabrigar, L.R., Wegener, D.T., MacCallum, R.C. and Strahan, E.J. (1999), "Evaluating the use of exploratory factor analysis in psychological research", Psychological Methods, Vol. 4 No. 3, pp. 272-99.

Field, A. (2013), Discovering Statistics Using SPSS, 4th ed., Sage Publishing, New York, NY.

Fleishman, E.A. (1967), "Development of a behavior taxonomy for describing human tasks: a correlationalexperimental approach”, Journal of Applied Psychology, Vol. 51 No. 1, pp. 1-10.

Fleishman, R. (1997), "Non-medical predictors of quality of care of hypertension in elderly patients", International Journal of Health Care Quality Assurance, Vol. 10 No. 3, pp. 107-16.

Forbes-Thompson, S. and Gessert, C.E. (2005), "End of life in nursing homes: connections between structure, process, and outcomes", Journal of Palliative Medicine, Vol. 8 No. 3, pp. 545-55.

Furnham, A. (2003), The Psychology of Behavior at Work, Taylor \& Francis, London.

Ghaye, T., Gillespie, D. and Lillyman, S. (2000), Empowerment Through Reflection:the Narratives of Healthcare Professionals, Mark Allen Publishing Group, Quay Books Division, London.

Hellström, U.W. and Sarvimäki, A. (2007), "Experiences of self-determination by older persons living in sheltered housing", Nursing Ethics, Vol. 14 No. 6, pp. 413-24.

Hu, L.T. and Bentler, P.M. (1999), "Cutoff criteria for fit indexes in covariance structure analysis: conventional criteria versus new alternatives”, Structural Equation Modeling: A Multidisciplinary Journal, Vol. 6 No. 1, pp. 1-55.

Hunter, B. (2004), "Conflicting ideologies as a source of emotion work in midwifery", Midwifery, Vol. 20 No. 3, pp. 261-72.

Kajonius, P. and Kazemi, A. (in pressa), "Safeness and treatment mitigate the effect of loneliness on satisfaction with elderly care", The Gerontologist.

Kajonius, P.J. and Kazemi, A. (in press b), "Structure and process quality as predictors of satisfaction with elderly care", Health and Social Care in the Community.

Kitwood, T. (1997), Dementia Reconsidered: The Person Comes First, Oxford Press, Oxford.

Lind, E.A. and Tyler, T.R. (1988), The Social Psychology of Procedural Justice, Plenum, New York, NY.

Lind, E.A., Kanfer, R. and Earley, P.C. (1990), "Voice, control and procedural justice: instrumental and noninstrumental concerns in fairness judgments", Journal of Personality and Social Psychology, Vol. 59 No. 5 , pp. 952-9.

Lothian, K. and Philp, I. (2001), "Care of older people: maintaining the dignity and autonomy of older people in the healthcare setting”, British Medical Journal, Vol. 322 No. 7287, pp. 668-70.

McCormack, B. (2004), "Person-centeredness in gerontological nursing: an overview of the literature", Journal of Clinical Nursing, Vol. 13 No. 1, pp. 31-8.

McDonald, S. and Simpson, B. (2014), "Shadowing research in organizations: the methodological debates", Qualitative Research in Organizations and Management: An International Journal, Vol. 9 No. 1, pp. 3-20.

Murphy, K., Shea, E.O. and Cooney, A. (2007), "Quality of life for older people living in long-stay settings in Ireland", Journal of Clinical Nursing, Vol. 16 No. 3, pp. 2167-77.

National Board of Health and Welfare (2008), Brukarinflytande inom äldreomsorgen, Socialstyrelsen, Stockholm.

National Board of Health and Welfare (2012), Open Comparisons, "Vård och omsorg om äldre 2012", Socialstyrelsen, Stockholm. 
Nolan, M., Davies, S., Brown, J., Keady, J. and Nolan, J. (2004), "Beyond 'person-centred' care: a new vision for gerontological nursing", International Journal of Older People Nursing, in association with Journal of Clinical Nursing, Vol. 13 No. 3a, pp. 45-53.

Olsen, G.M. (2013), "What's 'left' in the 'garden of Sweden'?", International Journal of Health Services, Vol. 43 No. 1, pp. 7-30.

Otani, K., Waterman, B. and Claiborne, D.W. (2012), "Patient satisfaction: how patient health conditions influence their satisfaction", Journal of Healthcare Management, Vol. 57 No. 4, pp. 276-92.

Persson, T. and Wästerfors, D. (2009), "Such trivial matters: how staff account for restrictions of residents' influence in nursing homes", Journal of Aging Studies, Vol. 23 No. 1, pp. 1-11.

Pink, S. (2007), Doing Visual Ethnography: Images, Media and Representation in Research, Sage, London.

Porter, M.E. (2009), "A strategy for health care reform - toward a value-based system", New England Journal of Medicine, Vol. 361 No. 2, pp. 109-12.

Senić, V. and Marinković, V. (2012), "Patient care, satisfaction and service quality in healthcare", International Journal of Consumer Studies, Vol. 9 No. 3, pp. 155-68.

Stewart, M. (2001), "Towards a global definition of patient centred care: the patient should be the judge of patient centred care”, British Medical Journal, Vol. 322 No. 7284, pp. 444-5.

Szymanski, D.M. and Henard, D.H. (2001), "Customer satisfaction: a meta-analysis of the empirical evidence", Journal of the Academy Marketing Science, Vol. 29 No. 1, pp. 16-35.

Tellis-Nayak, V. (2007), "A person-centered workplace: the foundation for person-centered caregiving in long-term care", Journal of the American Medical Directors Association, Vol. 8 No. 1, pp. 46-54.

Theobald, H. (2003), "Care for the elderly: welfare system, professionalisation and the question of inequality", International Journal of Sociology and Social Policy, Vol. 23 Nos 4/5, pp. 159-85.

\section{Further reading}

Cohen, J. (1992), "A power primer”, Psychological Bulletin, Vol. 112 No. 1, pp. 155-9.

Hemphill, J.F. (2003), "Interpreting the magnitudes of correlation coefficients", American Psychologist, Vol. 58 No. 1, pp. 78-80.

Statistics Sweden (2013), "Statistiska Centralbyrån, Befolkningspyramiden för Sverige: Andelen äldre fördubblad på 100 år”, SCB, Stockholm.

\section{About the authors}

Ali Kazemi is Associate Professor of Social Psychology at the School of Health and Education, University of Skövde, Sweden, and serves as the Co-Editor-in-Chief for the Social Justice Research (Springer). Associate Professor Ali Kazemi is the corresponding author and can be contacted at: ali.kazemi@his.se

Petri J. Kajonius is a Doctoral Candidate in the Division of Gerontology at the Department of Psychology, University of Gothenburg, Sweden, and active within the fields of personality and well-being.

For instructions on how to order reprints of this article, please visit our website:

www.emeraldgrouppublishing.com/licensing/reprints.htm

Or contact us for further details: permissions@emeraldinsight.com 